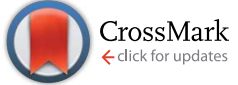

Cite this: J. Mater. Chem. A, 2014, 2 , 19407

Received 21st August 2014

Accepted 24th September 2014

DOI: $10.1039 / c 4 t a 04339 a$

www.rsc.org/MaterialsA

\section{Electrodeposited nickel-sulfide films as competent hydrogen evolution catalysts in neutral water $\dagger$}

\begin{abstract}
Nan Jiang, ${ }^{a}$ Lia Bogoev, ${ }^{a}$ Marina Popova, ${ }^{a}$ Sheraz Gul, ${ }^{b}$ Junko Yano ${ }^{b}$ and Yujie Sun ${ }^{\star a}$
The development of low-cost, efficient, and robust electrocatalysts of the hydrogen evolution reaction (HER) is a crucial step toward the conversion and storage of sustainable and carbon-neutral energy resources, such as solar energy. Not only the HER catalysts need to be composed of inexpensive elements, they are also desirable to be prepared at low energy cost. In this work, we report that nickelsulfide (Ni-S) films prepared by facile potentiodynamic deposition are active HER catalysts in aqueous media. Notably, the Ni-S films showed catalytic activity in water with a wide range of $\mathrm{pH}$ values (0 to 14), as well as in natural water. In $\mathrm{pH} 7$ phosphate buffer, a current density of $60 \mathrm{~mA} \mathrm{~cm}{ }^{-2}$ could be achieved with a Tafel slope of $77 \mathrm{mV} \mathrm{dec}{ }^{-1}$ and a Faradaic efficiency of $100 \%$. A long-term bulk electrolysis of the $\mathrm{Ni}-\mathrm{S}$ film exhibited steady current over $100 \mathrm{~h}$ with no deactivation, demonstrating its superior stability in neutral water. Further, an initial activation process was observed, which is likely due to the increase in the effective surface area of the Ni-S film under electrocatalytic conditions. A suite of characterization techniques, including X-ray photoelectron spectroscopy and X-ray absorption spectroscopy, were conducted to probe the composition and structure of the Ni-S film, revealing that its major component is $\mathrm{Ni}_{3} \mathrm{~S}_{2}$ which was preserved under electrocatalytic conditions.
\end{abstract}

\section{Introduction}

The growing global energy demands, depletion of fossil fuel reserves, as well as increasing concerns about climate change resulting from fossil fuel combustion have urged the exploration of green and sustainable energy resources. Solar energy is a promising candidate owing to its gigantic capacity. ${ }^{1}$ However, its diurnal and intermittent nature requires efficient capture and storage. In this respect, solar-driven water splitting to produce hydrogen and oxygen is an attractive means to store solar energy in chemical forms. ${ }^{2}$ Hydrogen, when generated from water with renewable energy input, is an ideal energy carrier with a minimal climate impact since water is the sole product of its combustion. ${ }^{2}$ In addition, hydrogen is also an important chemical feedstock, playing a crucial role in petroleum refining and $\mathrm{NH}_{3}$ synthesis for fertilizers. ${ }^{3}$ Thus, significant efforts have been devoted to developing efficient catalysts for the hydrogen evolution reaction (HER).

Solid-state catalysts employing noble metals, such as platinum, have long been recognized as competent HER catalysts with low overpotential and great stability, ${ }^{4}$ however the

${ }^{a}$ Department of Chemistry and Biochemistry, Utah State University, Logan, Utah 84322, USA. E-mail: yujie.sun@usu.edu; Fax: +1-435-797-3390; Tel: +1-435-797-7608 ${ }^{b}$ Physical Biosciences Division, Lawrence Berkeley National Laboratory, Berkeley, California 94720, USA

$\dagger$ Electronic supplementary information (ESI) available: Additional electrochemistry and characterization data, Tables S1 to S3 and Fig. S1 to S13. See DOI: 10.1039/c4ta04339a associated scarce and high cost limit their application on a large scale. It remains a great challenge to develop inexpensive HER catalysts exhibiting both high efficiency and strong robustness in aqueous media, preferably neutral water. ${ }^{5}$ Recent years have witnessed the emergence of several promising solid-state HER catalysts composed of earth-abundant elements. For example, molybdenum sulfides of varying morphologies have been reported to be active HER catalysts in strong acidic solution. ${ }^{6-10}$ $\mathrm{MoB},{ }^{11,12} \mathrm{Mo}_{2} \mathrm{C},{ }^{13,14}$ metal-doped molybdenum sulfides $\mathrm{M}-\mathrm{MoS}_{2}$ $\left(\mathrm{M}=\mathrm{Fe}, \mathrm{Co}, \mathrm{Ni}\right.$, etc.) ${ }^{15}$ and $\mathrm{Cu}_{2} \mathrm{MoS}_{4}$ (ref. 16) were also published recently showing good to excellent HER catalysis in acidic media. In addition, heterogeneous HER catalysts of first-row transition metals were also reported, such as $\mathrm{H}_{2}$-CoCat, ${ }^{17} \mathrm{MS}_{2}$ $(\mathrm{M}=\mathrm{Fe}, \mathrm{Co}, \mathrm{Ni}),{ }^{18} \mathrm{CoP},{ }^{19,20} \mathrm{CoSe}_{2},{ }^{21} \mathrm{Co}-\mathrm{NRCNT},{ }^{22} \mathrm{FeS},{ }^{23} \mathrm{FeP},{ }^{24}$ and $\mathrm{Ni}_{2} \mathrm{P}^{25}$ These catalysts are usually studied in a strong acidic electrolyte and some of them require toxic gas treatment at elevated temperature.

In order to minimize the environmental impact and increase the biocompatibility, it is very desirable to conduct hydrogen evolution in neutral water, which is the ultimate ideal solvent for water splitting. We recently reported that potentiodynamic deposition was able to produce cobalt-sulfide films as HER catalysts in neutral phosphate buffer. ${ }^{26}$ Herein, we describe that a slightly modified method enabled us to generate amorphous nickel-sulfide (Ni-S) films as well. Electrochemical experiments under various conditions demonstrate that the Ni-S films are very active HER catalysts in water over a wide range of $\mathrm{pH}$ values. The Ni-S film maintained its catalytic activity over $100 \mathrm{~h}$ 
in $\mathrm{pH} 7$ phosphate buffer with a Tafel slope of $77 \mathrm{mV} \mathrm{dec}^{-1}$ and a Faradaic efficiency of $100 \%$. X-ray photoelectron spectroscopy and X-ray absorption spectroscopy results revealed that the major composition of the Ni-S film is $\mathrm{Ni}_{3} \mathrm{~S}_{2}$, distinctive from the HER catalyst of $\mathrm{NiS}_{2}$ reported recently. ${ }^{18}$ To the best of our knowledge, this is the first time that amorphous Ni-S films prepared by potentiodynamic deposition are reported to exhibit efficient and robust hydrogen evolution catalysis in aqueous media, ranging from strong acidic to strong basic, as well as natural water.

\section{Results and discussion}

In a typical preparation of the Ni-S film, two thoroughly cleaned fluorine-doped tin oxide (FTO) electrodes were used as the working and counter electrodes, respectively, with an $\mathrm{Ag} / \mathrm{AgCl}$ electrode as the reference electrode. The potentiodynamic deposition was conducted with deoxygenated $5 \mathrm{mM} \mathrm{NiSO}_{4}$ and $0.5 \mathrm{M}$ thiourea in water. Linear voltammetry scans in the range of -1.2 to $0.2 \mathrm{~V} v s$. $\mathrm{Ag} / \mathrm{AgCl}$ were conducted at a scan rate of 5 $\mathrm{mV} \mathrm{s}^{-1}$ for a certain number of cycles (Fig. S1 $\dagger$ ). The cathodic scans of four samples prepared by $5,10,15$, and 20 cycles, respectively, are compared in Fig. $\mathrm{S} 2, \dagger$ where the one of the 15 cycles exhibits the best activity. Hence, the following experiments were conducted on Ni-S samples prepared with 15 cycles. Along the deposition process, the area of the FTO working electrode exposed to the electrolyte solution gradually turned black and a uniform film formed on the surface. At the end of deposition, the working electrode was rinsed with water gently and dried under vacuum at room temperature overnight, followed by annealing under nitrogen at $300{ }^{\circ} \mathrm{C}$ for $4 \mathrm{~h}$, which was found to strengthen the mechanic stability of the deposited film attached to FTO. The scanning electron microscopy (SEM) image of a typical Ni-S/FTO electrode is displayed in Fig. 1a, showing nearly complete coverage of the Ni-S film on FTO. No regular crystalline particles or aggregates were observed. Crosssectional SEM images of the deposited film indicate that the film thickness is around $700 \mathrm{~nm}$ (Fig. S3†). The presence of nickel and sulphur in the deposited film was confirmed by energy dispersive X-ray spectroscopy (EDS), Fig. S4. $†$ The signals of $\mathrm{Sn}, \mathrm{O}, \mathrm{Si}$, and $\mathrm{F}$ are attributed to the FTO-coated glass substrate. The powder X-ray diffraction (XRD) pattern of Ni-S/
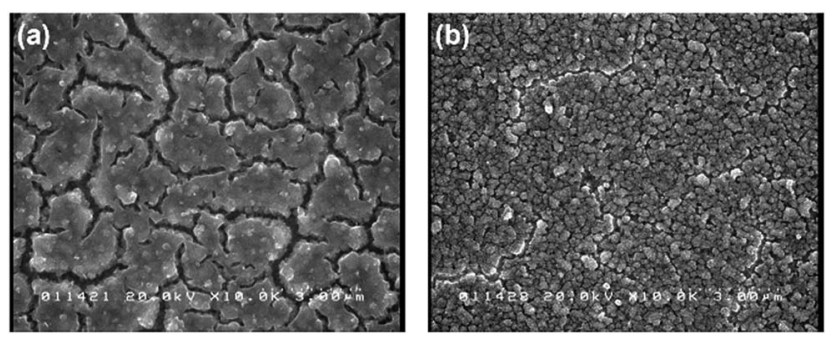

Fig. 1 SEM images of Ni-S/FTO before (a) and after (b) a 1 h electrolysis in $\mathrm{pH} 7$ phosphate buffer at $-0.689 \mathrm{~V}$ vs. SHE. The post-electrolysis $\mathrm{Ni}-$ $\mathrm{S}$ film displays a rougher and more porous surface compared to the pre-electrolysis one.
FTO is compared to that of a blank FTO as shown in Fig. S5. $\dagger$ All the XRD peaks are due to the presence of FTO, whereas no unique diffraction was noticed for the Ni-S film. Hence, it is concluded that the Ni-S film is amorphous in nature. Elemental analysis via inductively coupled plasma optical emission spectrometry (ICP-OES) for four Ni-S/FTO samples prepared with different surface areas indicates that the average mass loading of $\mathrm{Ni}$ is $81.50 \mu \mathrm{g} \mathrm{cm}^{-2}$ and the Ni/S ratio is close to 1.55 (Table $\mathrm{S} 1 \dagger)$.

The HER catalysis of the Ni-S film was first evaluated in neutral water. Fig. 2a shows the polarization curve of Ni-S/FTO in $\mathrm{pH} 7$ phosphate buffer at a scan rate of $2 \mathrm{mV} \mathrm{s}^{-1}$. The polarization curve of a blank FTO electrode is also included as a comparison. It is apparent that the blank FTO did not show any HER catalytic activity until $-0.95 \mathrm{~V} v s$. SHE, however a catalytic current was observed for Ni-S/FTO beyond $-0.55 \mathrm{~V} v s$. SHE (Fig. 2b). Further scanning towards negative potential produced a dramatic increase in current density, accompanied by vigorous growth and release of hydrogen bubbles from the electrode surface. To reach current densities of 1 and $10 \mathrm{~mA}$ $\mathrm{cm}^{-2}$, the Ni-S/FTO electrode required overpotentials of 227 and $330 \mathrm{mV}$, respectively. These values compare favorably with other solid-state earth-abundant HER catalysts at $\mathrm{pH} 7$ (Table S2 $\dagger$ ). Notably, the linear fitting of the Tafel plot (Fig. 2c) rendered a Tafel slope of $77 \mathrm{mV} \mathrm{dec}{ }^{-1}$, which is among the smallest Tafel slopes obtained for non-noble metal HER catalysts in neutral water. For instance, the $\mathrm{MoS}_{2}$ film showed a Tafel slope of 86 $\mathrm{mV} \mathrm{dec}{ }^{-1}$ at $\mathrm{pH} 7$, and the first-row transition metal doping in $\mathrm{MoS}_{2}$ did not decrease the Tafel slope (87-96 mV dec $\left.{ }^{-1}\right) .{ }^{15} \mathrm{An}$ electrodeposited nickel hydroxide/oxide film was reported to be active for hydrogen evolution catalysis, however it required an overpotential of $452 \mathrm{mV}$ to reach $1.5 \mathrm{~mA} \mathrm{~cm} \mathrm{~cm}^{-2}$ with a much larger Tafel slope (226 $\mathrm{mV} \mathrm{dec}^{-1}$ ) in a borate buffer (pH 9.2). ${ }^{27}$ Although the Co-S film prepared in a similar manner exhibited a better onset overpotential than the Ni-S film, the former possessed a larger Tafel slope (93 $\left.\mathrm{mV} \mathrm{dec}{ }^{-1}\right) .{ }^{26}$ Another elegant Janus cobalt catalyst prepared by electrodeposition showed a
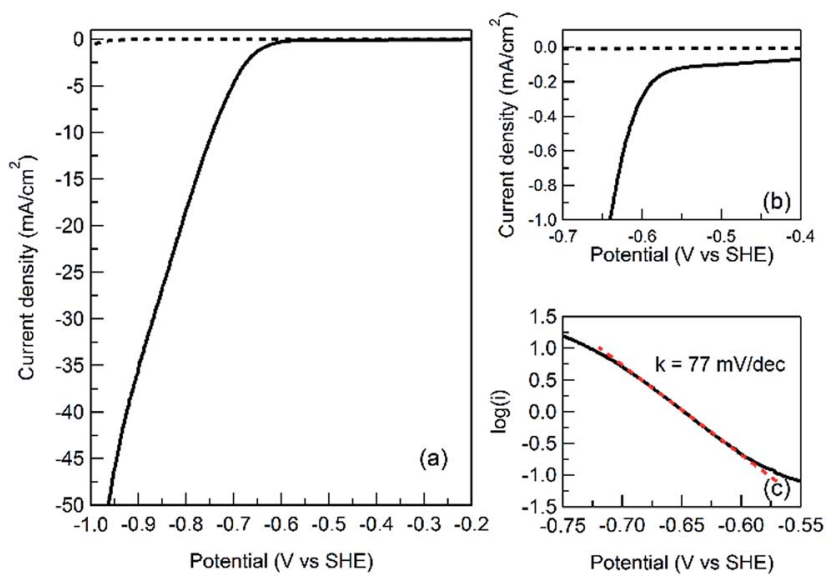

Fig. 2 ( $a$ and b) Polarizations of Ni-S/FTO (solid) and blank FTO (dotted) in $\mathrm{pH} 7$ phosphate buffer (scan rate: $2 \mathrm{mV} \mathrm{s}^{-1}$ ), and (c) the Tafel plot of Ni-S/FTO (black solid) with its linear fitting (red dotted) in the region of -0.55 to $-0.65 \mathrm{~V} v$ s. SHE. 
Tafel slope of $140 \mathrm{mV} \mathrm{dec}{ }^{-1}$ and required an overpotential of $\sim 325 \mathrm{mV}$ to reach $1 \mathrm{~mA} \mathrm{~cm}{ }^{-2} .^{17} \mathrm{NiS}_{2}$ (ref. 18) and $\mathrm{Ni}_{2} \mathrm{P}^{25}$ nanoparticles were recently reported showing HER catalytic activity, however they were studied in strong acidic media and no data in neutral water were available.

It was reported that three principal steps are involved in the hydrogen evolution reaction: Volmer (discharge), Tafel (recombination), and Heyrovsky (desorption) steps. ${ }^{28}$ Depending on which one is the limiting step, the Tafel slope could be 29,38 , or $116 \mathrm{mV} \mathrm{dec}^{-1}$, respectively. The deviation of the $77 \mathrm{mV}$ $\mathrm{dec}^{-1}$ slope of the Ni-S film from these three principal values indicates the complexity of the hydrogen evolution mechanism of this system. The detailed mechanistic understanding is under current investigation.

We next investigated the Faradaic efficiency of the Ni-S film in HER catalysis through a chronopotentiometry experiment maintaining a catalytic current of $2 \mathrm{~mA}$ for $2.5 \mathrm{~h}$. As shown in Fig. S6, $\uparrow$ the increasing amount of generated hydrogen was measured by gas chromatography and compared with the theoretical amount assuming that all the passed charges were used to produce hydrogen. The close match of the measured and calculated hydrogen volume demonstrates a $100 \%$ faradaic efficiency of Ni-S/FTO in HER electrocatalysis. Given the average loading mass of $\mathrm{Ni}\left(81.5 \mu \mathrm{g} \mathrm{cm}^{-2}\right.$, Table S1 $\left.\dagger\right)$, the mole of $\mathrm{Ni}$ $(0.534 \mu \mathrm{mol})$ in the Ni-S film is only $\sim 0.5 \%$ of the mole of hydrogen $(0.1 \mathrm{mmol})$ produced during the $2.5 \mathrm{~h}$ electrolysis.

In order to assess the long-term stability of the Ni-S film for HER catalysis, an extended electrolysis was carried out. Fig. 3a
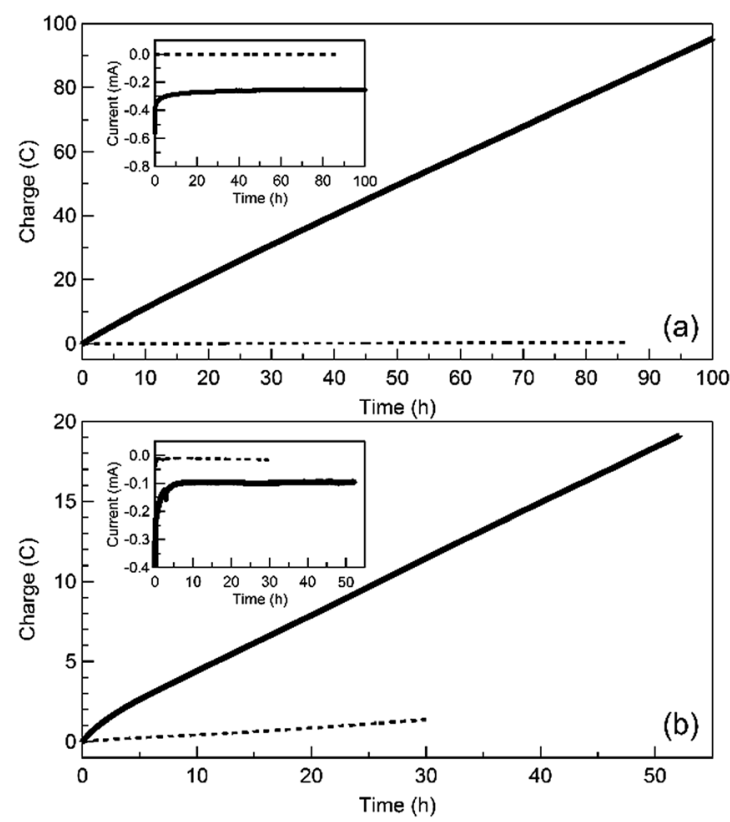

Fig. 3 Long-term controlled potential electrolysis of Ni-S/FTO (solid line) in (a) $1.0 \mathrm{M}$ phosphate buffer of $\mathrm{pH} 7$ at $-0.700 \mathrm{~V} v$ s. SHE and (b) filtered Great Salt Lake water at $-0.959 \mathrm{~V}$ vs. SHE. The insets in (a) and (b) show plots of the corresponding current change over time during the electrolysis experiments. The dashed lines in (a) and (b) represent the controlled potential electrolysis experiments of blank FTO electrodes conducted under the same conditions. presents the accumulated charge of Ni-S/FTO in pH 7 phosphate buffer at $-0.700 \mathrm{~V} v$ s. SHE for $100 \mathrm{~h}$. A nearly linear charge accumulation over time clearly demonstrates the robust durability of the Ni-S film for HER electrocatalysis, which is corroborated by the steady current over the entire course (Fig. 3a, inset). It should be noted that a blank FTO electrode only generated negligible charge build-up under the same conditions. Calculations from the average loading mass of $\mathrm{Ni}$ (Table S1 $\dagger$ ) and passed charge during the $100 \mathrm{~h}$ electrolysis resulted in a turnover number of 925 mole $\mathrm{H}_{2}$ per mole $\mathrm{Ni}$. It should be noted that this value only represents an underestimated activity of the Ni-S film, since catalysis is expected to occur at the active sites on the surface and the film has a thickness of $\sim 650 \mathrm{~nm}$ (Fig. S3†). From the very stable catalytic current over the entire electrolysis, it is highly anticipated that the Ni-S film will maintain its catalytic activity for a much longer duration than $100 \mathrm{~h}$.

Such a remarkable robustness of the Ni-S film prompted us to explore its catalytic performance under extreme conditions. Since the majority of solid-state HER catalysts reported recently were studied in strong acidic media, we first investigated the HER catalysis of Ni-S/FTO in $0.5 \mathrm{M} \mathrm{H}_{2} \mathrm{SO}_{4}$. As shown in Fig. S7, $\dagger$ $\mathrm{Ni}$-S/FTO was able to reach catalytic current densities of 1, 10, and $20 \mathrm{~mA} \mathrm{~cm} \mathrm{~cm}^{-2}$ at overpotentials of 150, 213, and $243 \mathrm{mV}$, respectively. A linear fitting of its Tafel plot resulted in a Tafel slope of $52 \mathrm{mV} \mathrm{dec}{ }^{-1}$ (Fig. S7, inset $\dagger$ ). These overpotentials and Tafel slope compare favorably to the values reported for other earth-abundant HER catalysts (Table S3 $\dagger$ ). An electrolysis of NiS/FTO at $-0.168 \mathrm{~V} v$ s. SHE was conducted for $90 \mathrm{~min}$ (Fig. S8†). The catalytic current decreased during the first half hour, followed by stabilization during the following hours. The initial decrease was likely due to the dissolution and/or detachment of the catalyst film from the FTO electrode. Nevertheless, the intrinsic electrocatalytic activity of Ni-S/FTO suggests that it is among the most active HER electrocatalysts in strong acidic media (Table $\mathrm{S} 3 \dagger$ ).

We next assessed the HER catalytic performance of the Ni-S film in $1.0 \mathrm{M} \mathrm{KOH}$. A catalytic current density of $20 \mathrm{~mA} \mathrm{~cm} \mathrm{~cm}^{-2}$ was achieved at $-1.05 \mathrm{~V}$ vs. SHE with a Tafel slope of $88 \mathrm{mV}$ $\operatorname{dec}^{-1}$ (Fig. S9†). A 7 h electrolysis of Ni-S/FTO at $-1.05 \mathrm{~V} v s$. SHE afforded an essentially linear charge build-up with no current decrease during the entire period (Fig. S10 $†$ ). It demonstrates the great stability of Ni-S/FTO in strong basic media.

Given the low cost and wide availability, natural water is an ideal substrate for water splitting. A natural water sample collected from the Great Salt Lake was filtered through a medium frit to remove insoluble particles and directly used as an electrolyte solution. As depicted in Fig. 3b, a long-term electrolysis of the Ni-S film was conducted in the Great Salt Lake water at $-0.959 \mathrm{~V} v s$. SHE over $50 \mathrm{~h}$. Despite an initial current decrease during the first few hours, the catalytic current stabilized and persisted for the rest of the period (Fig. 3b, inset). Hydrogen formation was confirmed by gas chromatography. A $30 \mathrm{~h}$ electrolysis of a blank FTO electrode did not generate an appreciable amount of hydrogen under the same conditions, implying that the species in the Great Salt Lake water were not able to form in situ HER catalysts that can compete with the Ni-S 
film. Overall, these results demonstrate that the Ni-S film is a competent and robust HER catalyst even in natural water.

During the electrocatalytic studies of the Ni-S film, an activation process was observed. As shown in Fig. S11, $\uparrow$ consecutive cathodic scans led to an increase in catalytic current and a stabilized current density was achieved after roughly 9 to 10 scans. To investigate the catalyst properties before and after electrochemical experiments, a controlled potential electrolysis of a freshly prepared Ni-S/FTO electrode was conducted at $-0.689 \mathrm{~V} v s$. SHE for $1 \mathrm{~h}$ (Fig. S12 $\dagger$ ). Electric impedance spectra of the Ni-S film before and after the $1 \mathrm{~h}$ electrolysis are compared in Fig. S13. $\dagger$ The Nyquist plots (Fig. S13b $\dagger$ ) indicate that there was no substantial resistance change of the catalyst film, showing a slight increase from 100 to $110 \Omega$. Therefore, resistance change can be ruled out as a cause of the enhanced activity.

It has been reported that cyclic voltammetry at non-Faradaic potentials is able to probe the electrochemical double layer as a means for estimating the effective electrode surface area. ${ }^{29}$ By plotting the difference in current density between the anodic and cathodic scans $\left(\Delta j=j_{\mathrm{a}}-j_{\mathrm{c}}\right)$ at a certain overpotential against the scan rate, a linear relationship could be obtained. Fitting these data to a straight line enables the extraction of the geometric double layer capacitance $\left(C_{\mathrm{dl}}\right)$, which is known to be proportional to the effective electrode surface area. The extracted slopes of these fitting lines allow a comparison of the relative surface areas of electrodes with different morphologies, especially when these electrodes consist of the same material. Fig. 4a and b present the cyclic voltammograms of a Ni-S/FTO electrode before and after the $1 \mathrm{~h}$ electrolysis (Fig. S12 $\dagger$ ) in the non-Faradaic region of -0.26 to $-0.16 \mathrm{~V} v s$. SHE. As the scan rate varied from 20 to $220 \mathrm{mV} \mathrm{s}^{-1}$, the cathodic and anodic current densities increased accordingly. Depicted in Fig. 4c are the plots of $\Delta j v s$. scan rate. The calculated capacitance of the post-electrolysis Ni-S film is $455.7 \mu \mathrm{F}$, nearly 34 times that before electrolysis $(13.5 \mu \mathrm{F})$, which indicates that the effective surface area of the post-electrolysis film is nearly 34 times that of the pre-electrolysis sample. This result is consistent with the rougher and more porous surface of the Ni-S film after electrolysis (Fig. 1b) compared to a fresh Ni-S film (Fig. 1a). A larger
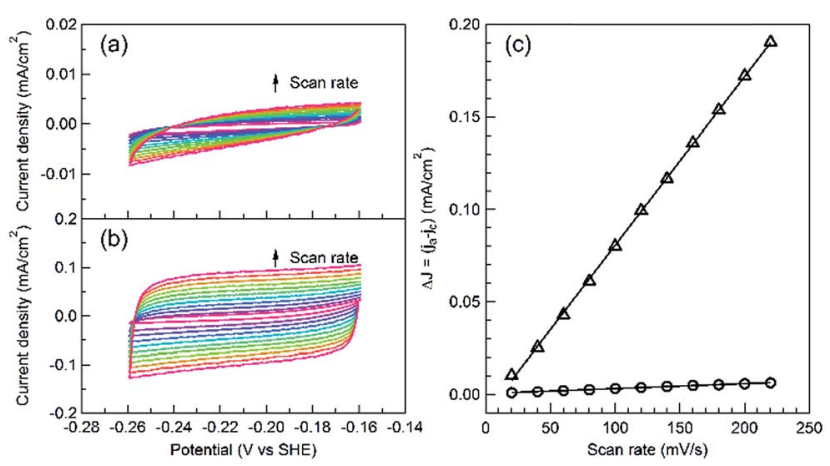

Fig. 4 Cyclic voltammograms of Ni-S/FTO in the non-Faradaic region before (a) and after (b) a $1 \mathrm{~h}$ electrolysis at $-0.689 \mathrm{~V}$ vs. SHE in $\mathrm{pH} 7$ phosphate buffer, and (c) scan rate dependence of the current densities of the pre- and post-electrolysis $\mathrm{Ni}-\mathrm{S}$ films at $-0.21 \mathrm{~V} v \mathrm{~s}$. SHE. surface area is able to provide more active sites for the hydrogen evolution reaction, leading to increased catalytic current density. ${ }^{15,21}$ Therefore, the observed activation process is probably due to the enhanced specific surface area resulting from surface reorganization under electrochemical conditions.

To further probe the surface composition of the Ni-S film, X-ray photoelectron spectroscopy (XPS) was conducted (Fig. 5). Fig. 5a includes the XPS survey spectra of the Ni-S films before and after the same $1 \mathrm{~h}$ electrolysis. Before electrolysis, all the observed peaks can be assigned to anticipated elements, including $\mathrm{Ni}$ and $\mathrm{S}$, in Ni-S/FTO. The Sn 3d and $3 \mathrm{p}$ peaks are attributed to the FTO substrate. It is worth noting that no Pt and/or Ag peaks were detected, indicating that Ni-S/FTO is free of noble metal impurities. The high-resolution region of $\mathrm{Ni} 2 \mathrm{p}$ spectra (Fig. 5b) shows peaks at 853.1 and $870.3 \mathrm{eV}$, corresponding to $\mathrm{Ni} 2 \mathrm{p}_{3 / 2}$ and $2 \mathrm{p}_{1 / 2}$, respectively. ${ }^{30}$ The shoulder around $855-860 \mathrm{eV}$ implies the presence of $\mathrm{Ni}(\mathrm{OH})_{2}$ and $\mathrm{NiSO}_{4} \cdot{ }^{30}$ XPS fitting of the Ni $2 \mathrm{p}_{3 / 2}$ peak of the pre- and postelectrolysis samples resulted in similar binding energies (Fig. S14 $\dagger$ ). For instance, the fitted peak at $853.04 \mathrm{eV}$ of the postelectrolysis sample is similar to those reported for $\mathrm{Ni}_{3} \mathrm{~S}_{2},{ }^{31} \mathrm{NiS},{ }^{32}$ and $\mathrm{NiS}_{2} \cdot{ }^{33}$ The similarity in the binding energy of the $\mathrm{Ni} 2 \mathrm{p}_{3 / 2}$ peak of different nickel sulfides is known. ${ }^{30}$ The process giving rise to the $\mathrm{Ni} 2 \mathrm{p}_{3 / 2}$ peak is mainly of metal ( $\mathrm{Ni}$ ) character, with little contribution from the surrounding ligand. This also explains why it is close to that of $\mathrm{Ni}$ metal $(852.5 \pm 0.2 \mathrm{eV}){ }^{30}$ Therefore, we cannot solely rely on the binding energy of the $\mathrm{Ni}$ $2 \mathrm{p}_{3 / 2}$ peak to determine the identity of nickel sulfide in the Ni-S film. Whereas, the simulated peaks at 854.73 and $857.00 \mathrm{eV}$ can be assigned to $\mathrm{Ni}(\mathrm{OH})_{2}$ and $\mathrm{NiSO}_{4}$, respectively. ${ }^{30}$ Spectral fitting of the high resolution region of the $S 2 p$ signal (Fig. S15†)
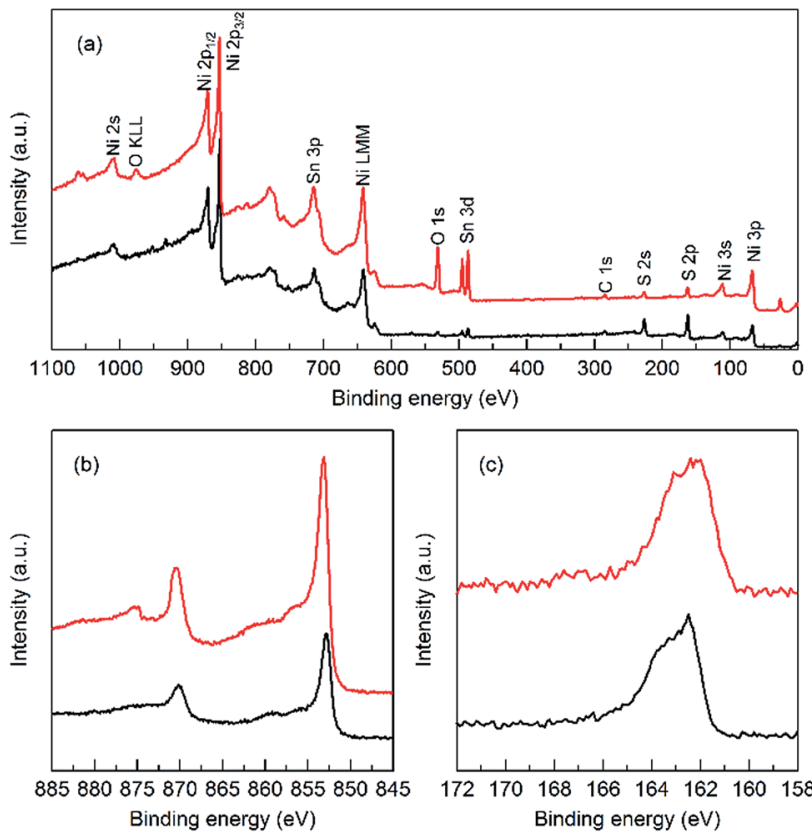

Fig. 5 XPS spectra of the Ni-S films before (black) and after (red) a $1 \mathrm{~h}$ electrolysis at $-0.689 \mathrm{~V} v$ s. SHE in $\mathrm{pH} 7$ phosphate buffer: (a) survey, (b) $\mathrm{Ni} 2 \mathrm{p}$ region, and (c) $\mathrm{S} 2 \mathrm{p}$ region. 
resulted in a doublet of 162.31 and $163.51 \mathrm{eV}$ (161.82 and 163.00 $\mathrm{eV}$ for the pre-electrolysis sample), corresponding to $\mathrm{S} 2 \mathrm{p}_{1 / 2}$ and $2 \mathrm{p}_{3 / 2}$, respectively.

In order to gain more insights into the atomic structure of the bulk Ni-S film, X-ray absorption spectroscopy was carried out. The Ni K-edge X-ray absorption near edge structure (XANES) and extended X-ray absorption fine structure (EXAFS) spectra of a Ni-S film before and after the $1 \mathrm{~h}$ electrolysis are shown in Fig. 6a and c, respectively. The XANES spectrum of the post-electrolysis sample is almost identical to that of the preelectrolysis counterpart, which confirms that the bulk catalyst film experienced little structural change during the electrolysis, while the surface morphology changed and the film became more porous as shown in Fig. 1. The Ni K-edge XANES spectrum of $\mathrm{Ni}(\mathrm{OH})_{2}$ is also included in Fig. 6a (blue trace) as a comparison. The drastic difference in the spectral shape and energy of the Ni-S film and $\mathrm{Ni}(\mathrm{OH})_{2}$ unambiguously rules out the latter as a major component of the film. In addition, compared with the reported XANES spectra of $\mathrm{Ni}^{34}{ }^{34 O},{ }^{34} \mathrm{NiS},{ }^{35,36}$ and $\mathrm{NiS}_{2},{ }^{35}$ the appreciable involvement of these species in the Ni-S film can also be excluded. In fact, the Ni K-edge XANES spectrum of the $\mathrm{Ni}-\mathrm{S}$ film resembles that of $\mathrm{Ni}_{3} \mathrm{~S}_{2}$ very well, which is further supported by the Ni EXAFS spectra (Fig. 6b). ${ }^{34,35} \mathrm{Ni}_{3} \mathrm{~S}_{2}$ (heazlewoodite) is one of the stable forms of nickel sulfides. ${ }^{37}$ Each nickel atom in crystalline $\mathrm{Ni}_{3} \mathrm{~S}_{2}$ occupies a pseudotetrahedral site in an approximately body-centered cubic sulfur lattice. ${ }^{38}$ The $\mathrm{N}_{3} \mathrm{~S}_{2}$ units are interconnected through short Ni-S and $\mathrm{Ni}-\mathrm{Ni}$ distances, 2.2914(5) and 2.5319(9) A, respectively, within the $\mathrm{Ni}_{3} \mathrm{~S}_{2}$ unit. However, the $\mathrm{Ni}-\mathrm{S}$ and $\mathrm{Ni}-\mathrm{Ni}$ distances are even shorter between $\mathrm{Ni}_{3} \mathrm{~S}_{2}$ units, being 2.2534(5) and 2.4966(4) A, respectively. Fig. 7 displays the crystal structure of $\mathrm{Ni}_{3} \mathrm{~S}_{2}$ and
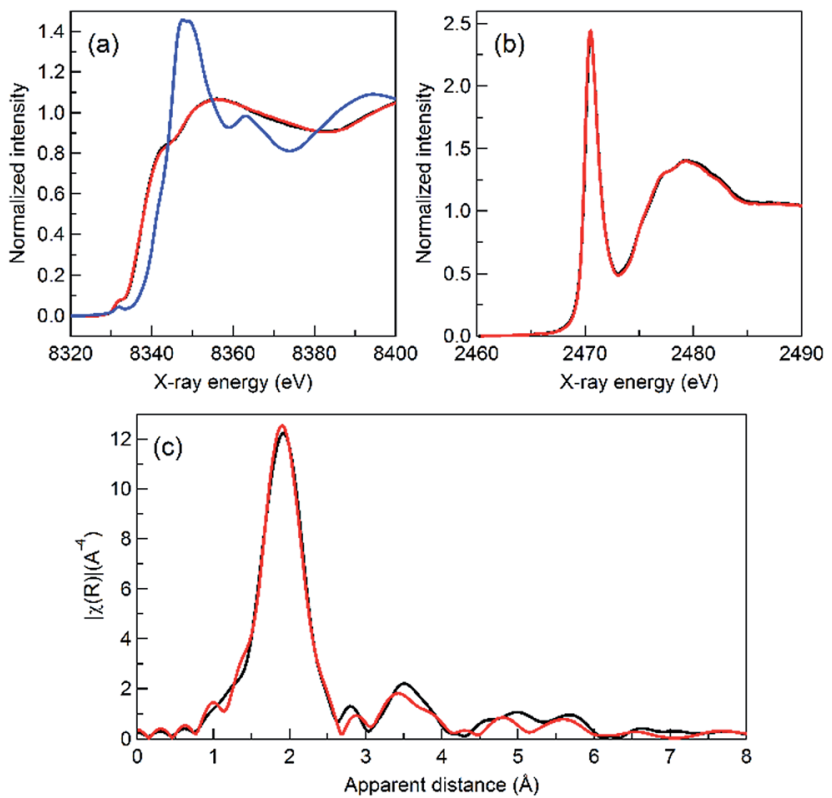

Fig. 6 Ni K-edge (a) and S K-edge (b) XANES spectra and Ni EXAFS spectra (c) of the Ni-S films before (black) and after (red) a $1 \mathrm{~h}$ electrolysis at $-0.689 \mathrm{~V} v$ s. SHE in $\mathrm{pH} 7$ phosphate buffer. The blue curve in (a) is the Ni K-edge XANES spectrum of $\mathrm{Ni}(\mathrm{OH})_{2}$ as a comparison.

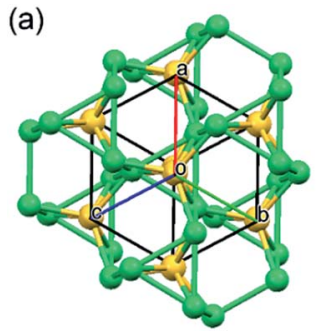

(b)

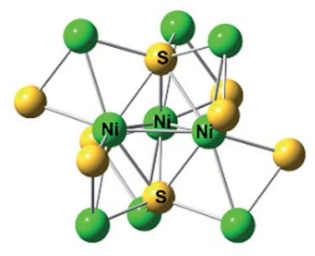

Fig. 7 (a) Crystal structure of $\mathrm{Ni}_{3} \mathrm{~S}_{2}$ viewed through the body diagonal direction; (b) selected region of the $\mathrm{Ni}_{3} \mathrm{~S}_{2}$ structure highlighting its trigonal bipyramidal core (green: nickel; yellow: sulfur). ${ }^{38}$

highlights its trigonal bipyramidal core. Ni EXAFS linear combination fitting of the post-electrolysis Ni-S film (Table S4 $\dagger$ ) suggests that its major component is $\mathrm{Ni}_{3} \mathrm{~S}_{2}$ with a small contribution of $\mathrm{Ni}(\mathrm{OH})_{2}(8 \%)$. The bond distances of Ni-S (2.27(0.04) $\mathrm{A})$ and Ni-Ni (2.51(0.04) $\mathrm{A})$ resulting from the EXAFS fitting well match those in the crystal structure of $\mathrm{Ni}_{3} \mathrm{~S}_{2}$. The short $\mathrm{Ni}-\mathrm{Ni}$ distances in $\mathrm{Ni}_{3} \mathrm{~S}_{2}$ have been proposed to be indicative of metal-metal bonding. ${ }^{37}$ Indeed, the fitted $\mathrm{Ni}-\mathrm{Ni}$ distance in the Ni-S film $(2.51 \AA)$ is very close to that in metallic nickel $(2.49 \AA) .{ }^{38 a}$ This result is also consistent with the close binding energy of the Ni $2 \mathrm{p}_{3 / 2}$ peak of the Ni-S film (Fig. $5 \mathrm{~b}$ ) and Ni metal. ${ }^{30}$ Overall, the combination of the XPS and XAS results, together with the ICP-OES data, unambiguously demonstrates that $\mathrm{Ni}_{3} \mathrm{~S}_{2}$ is the major composition of the Ni-S film.

\section{Conclusions}

In summary, we have demonstrated that amorphous Ni-S films prepared by facile potentiodynamic deposition are efficient, robust, and inexpensive HER catalysts in a variety of aqueous media, ranging from strong acidic, neutral, strong basic, to natural water. The catalyst possesses a Tafel slope of $77 \mathrm{mV}$ $\mathrm{dec}^{-1}$, a Faradaic efficiency of $100 \%$, and superior stability for at least $100 \mathrm{~h}$ at $\mathrm{pH}$ 7. An initial activation process was observed, which is likely due to the increased surface area of the Ni-S film resulting from surface reorganization under electrocatalytic conditions. Finally, surface and structural characterizations via SEM, EDS, ICP-OES, XRD, XPS, and XAS conclude the amorphous nature of the Ni-S film with a major composition of $\mathrm{Ni}_{3} \mathrm{~S}_{2}$, which was preserved during the electrochemical experiments. The detailed structural/activity investigation of the Ni-S film for hydrogen evolution requires in situ detection of the surface active sites under electrochemical conditions and is currently underway.

\section{Experimental section}

\section{Materials}

Nickel sulfate, thiourea, potassium hydroxide, potassium chloride, monobasic dihydrogen phosphate, dibasic monohydrogen phosphate, and sulfuric acid were all purchased from commercial vendors and used as received. Water was deionized $(18 \Omega)$ with a Barnstead E-Pure system. 


\section{Electrochemical methods}

Electrochemical experiments were performed on a Gamry Interface 1000 potentiostats. FTO electrodes $\left(8 \Omega \mathrm{cm}^{-1}\right)$ were purchased from Hartford Glass and cut into a size of $c a .1 \mathrm{~cm} \times$ $5 \mathrm{~cm}$ for electrochemical experiments. Aqueous $\mathrm{Ag} / \mathrm{AgCl}$ reference electrodes (saturated $\mathrm{KCl}$ ) were purchased from $\mathrm{CH}$ Instruments. The reference electrode in aqueous media was calibrated with ferrocenecarboxylic acid whose $\mathrm{Fe}^{3+/ 2+}$ couple is $0.284 \mathrm{~V} v s$. SCE. ${ }^{39}$ All potentials reported in this paper were converted from $v s$. SCE to $v s$. SHE by adding a value of $0.241 \mathrm{~V}$. $i R$ (current time internal resistance) compensation was applied in polarization and controlled potential electrolysis experiments to account for the voltage drop between the reference and working electrodes using Gamary Framework ${ }^{\mathrm{TM}}$ Data Acquisition Software 6.11. Electric impedance spectroscopy measurements were carried out in the same configuration at $-0.689 \mathrm{~V} v s$. SHE from $10^{5}$ to $0.1 \mathrm{~Hz}$ with an AC potential amplitude of $30 \mathrm{mV}$.

\section{Preparation of Ni-S/FTO electrodes}

Prior to electrodeposition, FTO electrodes were sonicated in acetone, water, and ethanol, consecutively. Each sonication was conducted for at least $15 \mathrm{~min}$. Subsequently, the FTO electrodes were rinsed with ethanol, dried, and stored under vacuum at room temperature. Scotch tape was used to cover the working FTO electrode with only a circular area of diameter of $7 \mathrm{~mm}$ exposed to the deposition solution $(5 \mathrm{mM}$ $\mathrm{NiSO}_{4}$ and $0.5 \mathrm{M}$ thiourea in water). Another blank FTO was used as the counter electrode with an $\mathrm{Ag} / \mathrm{AgCl}$ electrode as the reference electrode. Nitrogen was bubbled through the electrolyte solution for at least $20 \mathrm{~min}$ before deposition and maintained during the entire deposition process. The potential of consecutive linear scans was cycled between -1.2 and $0.2 \mathrm{~V} v s$. $\mathrm{Ag} / \mathrm{AgCl}$ at a scan rate of $5 \mathrm{mV} \mathrm{s}^{-1}$ under stirring. Fig. S1† shows typical cyclic voltammograms of the deposition of a Ni-S film on FTO. After deposition, the Ni-S/FTO electrode was removed from the deposition bath and rinsed with copious water gently. Ni-S/FTO was dried under vacuum at room temperature overnight, followed by annealing at 300 ${ }^{\circ} \mathrm{C}$ for $4 \mathrm{~h}$ under nitrogen. The prepared Ni-S/FTO electrodes were always stored under vacuum at room temperature prior to electrochemical experiments.

\section{Physical methods}

The generated hydrogen volume during electrolysis was quantified with a SRI gas chromatography system 8610C equipped with a molecular sieve $13 \times$ packed column, a HayesSep D packed column, and a thermal conductivity detector. The oven temperature was maintained at $60{ }^{\circ} \mathrm{C}$ and argon was used as the carrier gas. Scanning electron microscopy images were collected using a Hitachi S4000 scanning electron microscope. X-ray diffraction patterns were recorded on a Rigaku MiniflexII Desktop X-ray diffractometer. Nitrogen and sulfur analyses were carried out on a Thermo Electron iCAP inductively coupled plasma spectrophotometer.
X-ray photoelectron spectroscopy analyses were performed using a Kratos Axis Ultra instrument (Chestnut Ridge, NY) at the Surface Analysis Laboratory, University of Utah Nanofab. The samples were affixed on a stainless steel Kratos sample bar, loaded into the instrument's load lock chamber, and evacuated to $5 \times 10^{-8}$ torr before it was transferred into the sample analysis chamber under ultrahigh vacuum conditions $\left(\sim 10^{-10}\right.$ torr). X-ray photoelectron spectra were taken using the monochromatic $\mathrm{Al} \mathrm{K} \alpha$ source $(1486.7 \mathrm{eV})$ at a $300 \times 700 \mu \mathrm{m}$ spot size. Low resolution survey and high resolution region scans at the binding energy of interest were taken for each sample. To minimize charging, samples were flooded with low-energy electrons and ions from the instrument's built-in charge neutralizer. The samples were also sputter cleaned inside the analysis chamber with $1 \mathrm{keV} \mathrm{Ar}^{+}$ions for 30 seconds to remove adventitious contaminants and surface oxides. Data were analyzed using CASA XPS software, and energy corrections on high resolution scans were done by referencing the C1s peak of adventitious carbon to $284.5 \mathrm{eV}$.

X-ray absorption spectra were collected at the Stanford Synchrotron Radiation Lightsource (SSRL) on beamline 7-3 (Ni K-edge) and 4-3 (S K-edge) at an electron energy of $3.0 \mathrm{GeV}$ with an average current of $500 \mathrm{~mA}$. At beamline 7-3, the radiation was monochromatized by using a $\mathrm{Si}(220)$ doublecrystal monochromator. The intensity of the incident X-ray was monitored by using an $\mathrm{N}_{2}$-filled ion chamber $\left(I_{0}\right)$ in front of the sample. Data were collected as fluorescence excitation spectra with a Ge 30 element detector (Canberra). Energy was calibrated by the first peak maximum of the first derivative of a nickel foil XAS $(8333.0 \mathrm{eV})$. All data were collected at room temperature. The details of EXAFS curve fitting are included in the ESI. $\dagger$ At beamline 4-3, the incoming X-ray was monochromatized by using a $\mathrm{Si}(111)$ double-crystal monochromator. The intensity of the incident X-ray was monitored by using a He-filled ion chamber $\left(I_{0}\right)$ in front of the sample. Data were collected as fluorescence excitation spectra with a Vortex 4 element silicon drift detector (SII NanoTechnology). Monochromator energy was calibrated to the 1st peak of the thiosulfate reference sample, which was assigned at 2472.0 $\mathrm{eV}$. The sample environment was kept under a $\mathrm{He}$ gas atmosphere with a He-filled bag to reduce air absorption of incoming X-rays and fluorescence signals. The data were collected at room temperature.

\section{Acknowledgements}

N.J. acknowledges the Governor's Energy Leadership Scholars grant program of the State of Utah. L.B. is supported by the URCO and SURCO programs of Utah State University (USU). Y.S. acknowledges the financial support from USU and the Principle Energy Issues Program of the State of Utah. J.Y. is supported by the Director, Office of Science, Office of Basic Energy Sciences (OBES), Division of Chemical Sciences, Geosciences, and Biosciences of the Department of Energy (DOE) under Contract DE-AC02-05CH11231. XAS data collection was carried out at the Stanford Synchrotron Radiation Lightsource (SSRL) beamlines 7-3 and 4-3, operated by 
Stanford University for the U.S. DOE Office of Science, and supported by the DOE Office of Biological and Environmental Research, and by the NIH (including P41GM103393). SEM and EDS were conducted by FenAnn Shen at the Microscopy Core Facility of USU.

\section{Notes and references}

1 (a) A. J. Bard and M. A. Fox, Acc. Chem. Res., 1995, 28, 141145; (b) J. A. Turner, Science, 2004, 305, 972-974; (c) N. S. Lewis and D. G. Nocera, Proc. Natl. Acad. Sci. U. S. A., 2006, 103, 15729-15735; (d) H. B. Gray, Nat. Chem., 2009, 1, 7.

2 (a) M. G. Walter, E. L. Warren, J. R. McKone, S. W. Boettcher, Q. Mi, E. A. Santori and N. S. Lewis, Chem. Rev., 2010, 110, 6446-6473; (b) T. R. Cook, D. K. Dogutan, S. Y. Reece, Y. Surendranath, T. S. Teets and D. G. Nocera, Chem. Rev., 2010, 110, 6474-6502.

3 US Energy Information Administration, The Impact of Increased Use of Hydrogen on Petroleum Consumption and Carbon Dioxide Emissions, US Energy Information Administration, 2008.

4 (a) A. Fujishima and K. Honda, Nature, 1972, 238, 37-38; (b) E. Aharon-Shalom and A. Heller, J. Electrochem. Soc., 1982, 129, 2865-2866; (c) X. Chen, S. Shen, L. Guo and S. S. Mao, Chem. Rev., 2010, 110, 6503-6570.

5 V. S. Thoi, Y. Sun, J. R. Long and C. J. Chang, Chem. Soc. Rev., 2013, 42, 2388-2400.

6 (a) T. F. Jaramillo, K. P. Jorgensen, J. Bonde, J. H. Nielsen, S. Horch and I. Chorkendorff, Science, 2007, 317, 100-102; (b) J. Bonde, P. G. Moses, T. F. Jaramillo, J. K. Norskov and I. Chorkendorff, Faraday Discuss., 2009, 140, 219-231; (c) J. D. Benck, Z. Chen, L. Y. Kuritzky, A. J. Forman and T. F. Jaramillo, ACS Catal., 2012, 2, 1916-1923.

7 (a) D. Merki, S. Fierro, H. Vrubel and X. Hu, Chem. Sci., 2011, 2, 1262-1267; (b) D. Merki and X. Hu, Energy Environ. Sci., 2011, 4, 3878-3888.

8 H. Vrubel, D. Merki and X. Hu, Energy Environ. Sci., 2012, 5, 6136-6144.

9 (a) J. Kibsgaard, Z. Chen, B. N. Reinecke and T. F. Jaramillo, Nat. Mater., 2012, 11, 963-969; (b) Z. Chen, D. Cummins, B. N. Reinecke, E. Clark, M. K. Sunkara and T. F. Jaramillo, Nano Lett., 2011, 11, 4168-4175.

10 (a) Y. Li, H. Wang, L. Xie, Y. Liang, G. Hong and H. Dai, J. Am. Chem. Soc., 2011, 133, 7296-7299; (b) M. L. Tang, D. C. Grauer, B. Lassalle-Kaiser, V. K. Yachandra, L. Amirav, J. R. Long, J. Yano and A. P. Alivisatos, Angew. Chem., Int. Ed., 2011, 50, 10203-10207.

11 H. Vrubel and X. Hu, Angew. Chem., Int. Ed., 2012, 51, 1270312706.

12 M. D. Scanlon, X. Bian, H. Vrubel, V. Amstutz, K. Schenk, X. Hu, B. Liu and H. H. Girault, Phys. Chem. Chem. Phys, 2013, 15, 2847-2857.

13 L. Liao, S. Wang, J. Xiao, X. Bian, Y. Zhang, M. D. Scanlon, X. Hu, Y. Tang, B. Liu and H. H. Girault, Energy Environ. Sci., 2014, 7, 387-392.

14 (a) W.-F. Chen, S. Iyer, S. Iyer, K. Sasaki, C.-H. Wang, Y. Zhu, J. T. Muckerman and E. Fujita, Energy Environ. Sci., 2013, 6,
1818-1826; (b) W.-F. Chen, J. T. Muckerman and E. Fujita, Chem. Commun., 2013, 49, 8896-8909.

15 D. Merki, H. Vrubel, L. Rovelli, S. Fierro and X. Hu, Chem. Sci., 2012, 3, 2515-2525.

16 P. D. Tran, M. Nguyen, S. S. Pramana, A. Bhattacharjee, S. Y. Chiam, J. Fize, M. J. Field, V. Artero, L. H. Wong, J. Loo and J. Barber, Energy Environ. Sci., 2012, 5, 8912-8916.

17 S. Cobo, J. Heidkamp, P.-A. Jacques, J. Fize, V. Fourmond,

L. Guetaz, B. Jousselme, V. Ivanova, H. Dau, S. Palacin,

M. Fontecave and V. Artero, Nat. Mater., 2012, 11, 802-807.

18 D. Kong, J. J. Cha, H. Wang, H. R. Lee and Y. Cui, Energy Environ. Sci., 2013, 6, 3553-3558.

19 E. J. Popczun, C. G. Read, C. W. Roske, N. S. Lewis and R. E. Schaak, Angew. Chem., Int. Ed., 2014, 53, 5427-5430.

20 Q. Liu, J. Tian, W. Cui, P. Jiang, N. Cheng, A. M. Asiri and X. Sun, Angew. Chem., Int. Ed., 2014, 53, 6710-6714.

21 D. Kong, H. Wang, Z. Lu and Y. Cui, J. Am. Chem. Soc., 2014, 136, 4897-4900.

22 X. Zou, X. Huang, A. Goswami, R. Silva, B. R. Sathe, E. Mikmeková and T. Asefa, Angew. Chem., Int. Ed., 2014, 53, 4372-4376.

23 C. Di Giovanni, W.-A. Wang, S. Nowak, J.-M. Grenèche, H. Lecoq, L. Mouton, M. Giraud and C. Tard, ACS Catal., 2014, 681-687.

24 Y. Xu, R. Wu, J. Zhang, Y. Shi and B. Zhang, Chem. Commun., 2013, 49, 6656-6658.

25 (a) E. J. Popczun, J. R. McKone, C. G. Read, A. J. Biacchi, A. M. Wiltrout, N. S. Lewis and R. E. Schaak, J. Am. Chem. Soc., 2013, 135, 9267-9270; (b) L. Feng, H. Vrubel, M. Bensimon and X. Hu, Phys. Chem. Chem. Phys., 2014, 16, 5917-5921.

26 Y. Sun, C. Liu, D. C. Grauer, J. Yano, J. R. Long, P. Yang and C. J. Chang, J. Am. Chem. Soc., 2013, 135, 17699-17702.

27 C. He, X. Wu and Z. He, J. Phys. Chem. C, 2014, 118, 45784584.

28 (a) J. O. M. Bockris and E. C. Potter, J. Electrochem. Soc., 1952, 99, 169-186; (b) B. E. Conway, L. Bai and M. A. Sattar, Int. J. Hydrogen Energy, 1987, 12, 607-621.

29 E. Gileadi, Physical Electrochemistry, Wiley-VCH, Weinheim, 2011.

30 H. W. Nesbitt, D. Legrand and G. M. Bancroft, Phys. Chem. Miner., 2000, 27, 357-366.

31 A. N. Buckley and R. Woods, J. Appl. Electrochem., 1991, 21, 575-582.

32 D. L. Legrand, H. W. Nesbitt and G. M. Bancroft, Am. Mineral., 1998, 83, 1256-1265.

33 L. Sangaletti, F. Parmigiani, T. Thio and J. W. Bennett, Phys. Rev. B: Condens. Matter Mater. Phys., 1997, 55, 9514.

34 L. Huang, G. Wang, Z. Qin, M. Dong, M. Du, H. Ge, X. Li, Y. Zhao, J. Zhang, T. Hu and J. Wang, Appl. Catal., B, 2011, 106, 26-38.

35 R. P. W. J. Struis, T. J. Schildhauer, I. Czekaj, M. Janousch, S. M. A. Biollaz and C. Ludwig, Appl. Catal., A, 2009, 362, 121-128.

36 A. V. Soldatov, A. N. Kravtsova, M. E. Fleet and S. L. Harmer, J. Phys.: Condens. Matter, 2004, 16, 7545-7556. 
37 D. J. Vaughan and J. R. Craig, Mineral Chemistry of Metal Sulfides, Cambridge University Press, Cambridge, 1978.

38 (a) J. Parise, Acta Crystallogr., Sect. B: Struct. Crystallogr. Cryst. Chem., 1980, 36, 1179-1180; (b) P. A. Metcalf, P. Fanwick,
Z. Kạkol and J. M. Honig, J. Solid State Chem., 1993, 104, 81-87.

39 E. Liaudet, F. Battaglini and E. J. Calvo, J. Electroanal. Chem. Interfacial Electrochem., 1990, 293, 55-68. 